\title{
A Quantitative Assessment Framework for Water, Energy and Food Nexus
}

\author{
Ali Karnib \\ Lebanese University, Hadath Campus, Baabda, Lebanon \\ Email:karnib.ali@gmail.com
}

How to cite this paper: Karnib, A. (2017) A Quantitative Assessment Framework for Water, Energy and Food Nexus. Computational Water, Energy, and Environmental Engineering, 6, 11-23.

http://dx.doi.org/10.4236/cweee.2017.61002

Received: September 11, 2016

Accepted: November 26, 2016

Published: November 29, 2016

Copyright $\odot 2017$ by author and Scientific Research Publishing Inc. This work is licensed under the Creative Commons Attribution International License (CC BY 4.0).

http://creativecommons.org/licenses/by/4.0/

\begin{abstract}
This paper presents a quantitative assessment framework of the Water, Energy and Food (W-E-F) nexus. The proposed approach allows integrated quantitative assessments by considering all the W-E-F intersectoral linkages and the competing demand for W-E-F resources to evaluate future development scenarios. Firstly, the conceptual model adopted for the proposed framework is presented. Secondly, a detailed methodological framework is introduced to serve as W-E-F nexus evaluation and planning platform. At the practical level, the model is applied to evaluate the W-E-F nexus in Lebanon. Finally, the conclusions and further developments are presented.
\end{abstract}

\section{Keywords}

Water, Energy, Food, Nexus Approach, Sustainable Development

\section{Introduction}

The importance of the Water, Energy, Food (W-E-F) nexus has been gaining global momentum over the last few years. The water, energy and food sectors are interdependent while each faces their own specific supply risks in the face of increases in demand driven by population growth and mobility, climate change, urbanization, economic development, international trade and technological changes [1] [2] [3]. Decision-makers need holistic approaches in order to be better informed about the trade-offs and synergies between the various development and management options, and to help them identify choices on how to manage and plan these resources in a sustainable manner [1] [4] [5].

A growing number of international development organizations, scientists and groups of research have sought to develop water, energy and food nexus frameworks and methods to promote sustainable and efficient resource use [4] [6]-[15]. The literature features different conceptualizations of the nexus which vary in their scope, goals, and 
understanding of drivers and pressures. A review of the conceptual frameworks and methodologies advanced on the W-E-F nexus approaches could be found in [16] [17] and [18]. Despite the methodological varieties of these models, they have only covered partial aspects of the nexus and they share the difficulty of investigating the W-E-F nexus quantitatively.

The present study is developing a quantitative assessment framework for water, energy and food nexus that allows to analyze the intersectoral quantitative usage and resources demands and to plan future W-E-F developments in inclusive and consistent way. W-E-F nexus in Lebanon is analyzed as case study in order to put the proposed methodology in practice and to verify reliability of the proposed approach.

\section{The Proposed Approach}

\subsection{The Preliminary Theoretical Model}

The proposed framework is based on the balance of the water, energy and food total quantities through two main quantitative conceptual elements: 1) the intersectoral use quantities matrix $(Z)$ and 2 ) the final demand quantities vector $(y)$. The sum of these two components gives the total resources quantities vector $(x)$. By adopting this approach, the balance quantitative equation will be as follows:

$$
Z i+y=x \text {. }
$$

The final demand quantities vector $(y)$ are those to be used in the socio-economic system which cover households demands, government demands, rest of the economy demands, losses, accumulation (storage) and exports.

The intersectoral use quantities matrix $(Z)$ and the total resources quantities vector $(x)$ are related by an intersectoral intensity coefficients matrix that will be addressed in detail in the next paragraph.

Figure 1 presents a preliminary conceptual model of the water, energy and food nexus. The model shows links between the proposed W-E-F nexus model and DRIVERS and INTERVENORS changes. The DRIVERS are the effects of technological

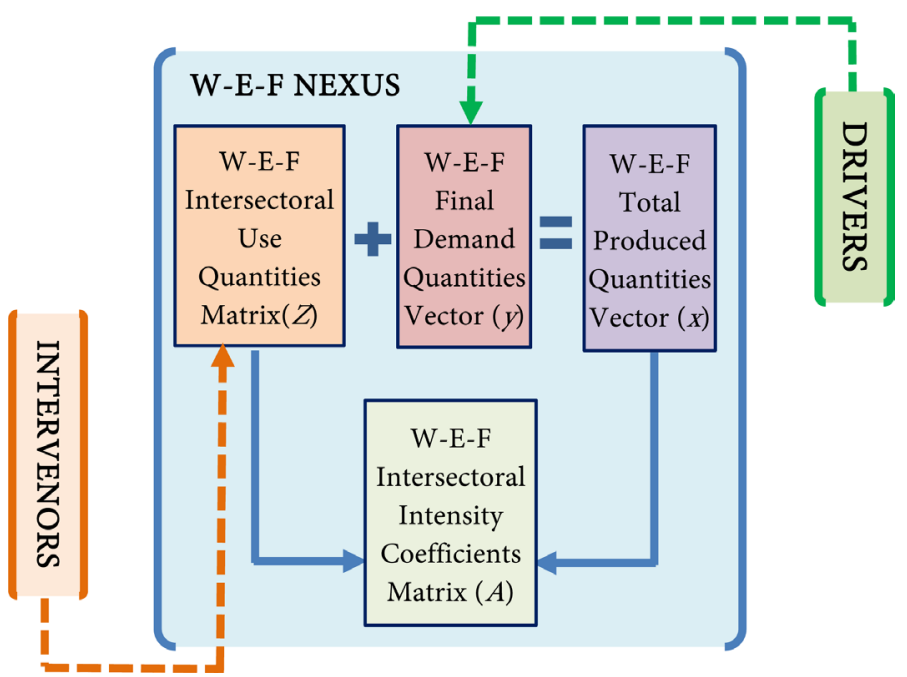

Figure 1. A preliminary conceptual model of the water, energy and food (W-E-F) nexus. 
change, global environmental change, demographic change and consumption patterns. The INTERVENORS are the effects of governance, management, operation and technological adoption.

The proposed W-E-F nexus framework mentioned above could be balanced at the present or any past year, and at any domain level (local, national, regional and global); and the effects of a particular projected change due to DRIVERS and/or INTERVENORS on the W-E-F intersectoral use quantities could be assessed.

\subsection{The Detailed Methodology}

In order to complete the resources quantitative balance, the proposed method of $\mathrm{W}$-E-Fnexus is established by considering the nine intersectoral relationships between water, energy and food: 1) water for water; 2) water for energy; 3) water for food; 4) energy for water; 5) energy for energy; 6) energy for food; 7) food for water; 8) food for energy and 9) food for food.

It is clear that, in terms of quantitative values, some of these relationships are more important than the others. The water for water and food for water relationships are quantitatively negligible or equal to zero. Therefore, these two relationships will be set equal to zero in our model.

If we denote by:

$n$ number of water resources inflows (i.e. surface water, groundwater, desalination, ...);

$m$ number of energy resources inflows (i.e. petroleum, natural gas, electricity, renewable energy, ...);

$h$ number of food resources inflows (i.e. irrigated crop, animal production, fisheries, ...);

$Z_{i j}^{W} \perp^{e}$ : the use of $i^{t h}$ water resource in the $j^{\text {th }}$ energy resource (water for energy);

$z_{i j}^{w}-f$ : the use of $i^{\text {th }}$ water resource in the $j^{\text {th }}$ food resource (water for food);

$Z_{i j}^{e-w}$ : the use of $i^{t h}$ energy resource in the $j^{\text {th }}$ water resource (energy for water);

$z_{i j}^{e_{-}{ }^{e}}$ : the use of $i^{t h}$ energy resource in the $j^{\text {th }}$ energy resource (energy for energy);

$z_{i j}^{e-f}$ : the use of $i^{\text {th }}$ energy resource in the $f^{t h}$ food resource (energy for food).

$z_{i j}^{f}-^{e}$ : the use of $i^{\text {th }}$ food resource in the $j^{\text {th }}$ energy resource (food for energy);

$z_{i j}^{f-f}$ : the use of $i^{\text {th }}$ food resource in the $f^{\text {th }}$ food resource (food for food).

The proposed framework of water, energy and food nexus model is as follows (Figure 2).

In Figure 2 horizontally three classes of W-E-F quantitative balance equations could be introduced as follows:

$$
\begin{gathered}
\sum_{j=1}^{m} z_{i j}^{w}{ }^{e}+\sum_{j=1}^{h} z_{i j}^{w}-f+y_{i}^{w}=x_{i}^{w} \quad(i=1,2, \cdots, n) \\
\sum_{j=1}^{n} z_{i j}^{e^{-}}+\sum_{j=1}^{m} z_{i j}^{e-e}+\sum_{j=1}^{h} z_{i j}^{e-f}+y_{i}^{e}=x_{i}^{e} \quad(i=1,2, \cdots, m) \\
\sum_{j=1}^{m} z_{i j}^{f-e}+\sum_{j=1}^{h} z_{i j}^{f-f}+y_{i}^{f}=x_{i}^{f} \quad(i=1,2, \cdots, h)
\end{gathered}
$$

where $x_{i}^{w}, x_{i}^{e}, x_{i}^{f}$ are the total use of the $i^{\text {th }}$ water resource, total use of the $i^{\text {th }}$ energy 


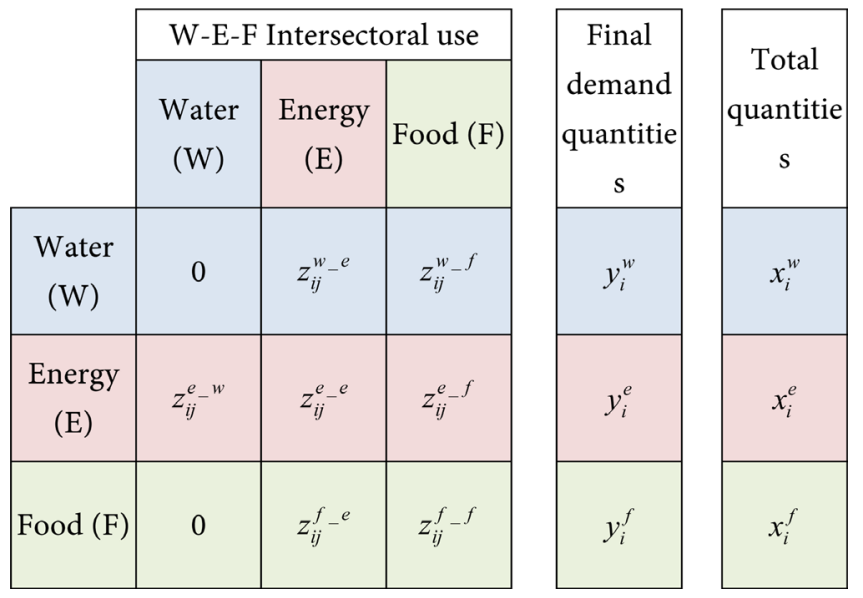

Figure 2. Proposed framework of water, energy and food nexus model.

resource and total use of the $i^{\text {th }}$ food resource, respectively.

In above equations, we introduce the following W-E-F nexus intensity coefficients ${ }^{1}$ : $a_{i j}^{w_{-} e}=\frac{z_{i j}^{w_{-}} e^{e}}{x_{j}^{e}} \quad$ (water for energy), $a_{i j}^{w}-f=\frac{z_{i j}^{w} f}{x_{j}^{f}} \quad$ (water for food), $a_{i j}^{e-w}=\frac{z_{i j}^{e}-^{w}}{x_{j}^{w}} \quad$ (energy for water), $a_{i j}^{e_{-} e}=\frac{z_{i j}^{e_{-} e}}{x_{j}^{e}}$ (energy for energy), $a_{i j}^{e_{-} f}=\frac{z_{i j}^{e_{-} f}}{x_{j}^{f}}$ (energy for food), $a_{i j}^{f-e}=\frac{z_{i j}^{f}-^{e}}{x_{j}^{e}}$ (food for energy) and $a_{i j}^{f-f}=\frac{z_{i j}^{f-f}}{x_{j}^{f}}$ (food for food).

Then Equations (2) (3) and (4) become:

$$
\begin{gathered}
\sum_{j=1}^{m} a_{i j}^{w}{ }^{e} X_{j}^{e}+\sum_{j=1}^{h} a_{i j}^{w}-f X_{j}^{f}+y_{i}^{w}=x_{i}^{w} \quad(i=1,2, \cdots, n) \\
\sum_{j=1}^{n} a_{i j}^{e-w} x_{j}^{w}+\sum_{j=1}^{m} a_{i j}^{e}-e x_{j}^{e}+\sum_{j=1}^{h} a_{i j}^{e-f} x_{j}^{f}+y_{i}^{e}=x_{i}^{e} \quad(i=1,2, \cdots, m) \\
\sum_{j=1}^{m} a_{i j}^{f-e} x_{j}^{e}+\sum_{j=1}^{h} a_{i j}^{f-f} x_{j}^{f}+y_{i}^{f}=x_{i}^{f} \quad(i=1,2, \cdots, h)
\end{gathered}
$$

where $x_{j}^{w}, x_{j}^{e}$ and $x_{j}^{f}$ are the total use of water resources sectors, energy sectors and food sectors, respectively.

Equations (5) (6) and (7) can be written in matrix form:

$$
\begin{gathered}
A^{w-e} X^{e}+A^{w-f} X^{f}+y^{w}=x^{w} \\
A^{e-w^{w}} X^{w}+A^{e-e} X^{e}+A^{e-f} X^{f}+y^{e}=x^{e} \\
A^{f-e} X^{e}+A^{f-f} X^{f}+y^{f}=x^{f} .
\end{gathered}
$$

In block matrix form:

$$
\left[\begin{array}{ccc}
0 & A^{w-e} & A^{w-f} \\
A^{e-w} & A^{e_{-} e} & A^{e_{-} f} \\
0 & A^{f-e} & A^{f-f}
\end{array}\right]\left[\begin{array}{c}
x^{w} \\
x^{e} \\
x^{f}
\end{array}\right]+\left[\begin{array}{c}
y^{w} \\
y^{e} \\
y^{f}
\end{array}\right]=\left[\begin{array}{c}
x^{w} \\
x^{e} \\
x^{f}
\end{array}\right]
$$

${ }^{1}$ Intensity coefficients may be referred also as "footprints". 
where

$$
A=\left[\begin{array}{ccc}
0 & A^{w_{-} e} & A^{w_{-} f} \\
A^{e_{-} w} & A^{e_{-} e} & A^{e_{-} f} \\
0 & A^{f_{-} e} & A^{f-f}
\end{array}\right] \text { is the W-E-F nexus technology matrix. }
$$

Then we have

$$
\left[\begin{array}{c}
x^{w} \\
x^{e} \\
x^{f}
\end{array}\right]=L\left[\begin{array}{l}
y^{w} \\
y^{e} \\
y^{f}
\end{array}\right]
$$

where:

$$
L=\left[\begin{array}{ccc}
I & -A^{w_{-} e} & -A^{w_{-} f} \\
-A^{e_{-} w} & I-A^{e_{-} e} & -A^{e_{-} f} \\
0 & -A^{f_{-} e} & I-A^{f_{-} f}
\end{array}\right]^{-1} .
$$

$L$ is known as the Leontief inverse or the total requirements matrix [19]. The whole core of the W-E-F nexus is contained in the matrix $L$. Final demands play a key role due to the increases in global demand driven by population growth, urbanization, changing lifestyles and diets, and climate change. The proposed model enabled policy makers to estimate the outputs in W-E-F sectors that were necessary in order to satisfy any vector of final demands. When the $y^{w}, y^{e}, y^{f}$ for a certain period are projected the values of the total demand $x^{w}, x^{e}, x^{f}$ can be calculated by Equation (12).

\subsection{The W-E-F Nexus Indicators}

In this section we will present the W-E-F nexus indicators that could be calculated based on the proposed methodology presented in section 2.2. The indicators are related to the W-E-F intersectoral use quantities $(z)$ and the intensity coefficients (a) and they are as follows:

\section{Water for energy indicators:}

1) Water use in the $j^{\text {th }}$ energy inflow $z_{j}^{w_{-} e}=\sum_{i=1}^{n} z_{i j}^{w_{-} e} \quad\left(M \cdot \mathrm{m}^{3}\right)$ (million cubic meter);

2) Energy-related water usage $\left(z^{w_{-} e}\right) \quad z^{w_{-} e}=\sum_{j=1}^{m} \sum_{i=1}^{n} z_{i j}^{w_{-} e} \quad\left(\mathrm{M} \cdot \mathrm{m}^{3}\right)$;

3) Proportion of the energy-related water usage per the total water usage (\%);

4) Intensity of water use (may be referred also as water footprint) in the $f^{\text {th }}$ energy inflow $a_{j}^{w_{-} e}=\frac{z_{j}^{w_{-} e}}{x_{j}^{e}} \quad\left(\mathrm{~m}^{3} /\right.$ toe $)$ (meter cube per tonne of oil equivalent);

5) Intensity of energy-related water usage (may be referred also as water footprint of energy) $a^{w_{-} e}=\frac{z^{w_{-} e}}{x^{e}}\left(\mathrm{~m}^{3} /\right.$ toe $)$.

\section{Water for food indicators:}

1) Water use in the $f^{\text {th }}$ food resource production $z_{j}^{w_{-} f}=\sum_{i=1}^{n} z_{i j}^{w_{-}} f \quad\left(\mathrm{M} \cdot \mathrm{m}^{3}\right)$;

2) Food-related water usage $z^{w_{-} f}=\sum_{j=1}^{h} \sum_{i=1}^{n} z_{i j}^{w_{-} f}\left(\mathrm{M} \cdot \mathrm{m}^{3}\right)$;

3) Proportion of the food-related water usage to the total water usage (\%);

4) Intensity of water use in the $j^{\text {th }}$ food resource production $a_{j}^{w_{-} f}=\frac{z_{j}^{w_{-}} f}{x_{j}^{f}}\left(\mathrm{~m}^{3} / \mathrm{t}\right)$ (meter cube per tonne); 
5) Intensity of food-related water usage (may be referred also as water footprint of food) $a^{w_{-} f}=\frac{z^{w_{-} f}}{x^{f}}\left(\mathrm{~m}^{3} / \mathrm{t}\right)$.

\section{Energy for water indicators:}

1) Energy use in the $f^{\text {th }}$ water resource production $z_{j}^{e_{-} w}=\sum_{i=1}^{m} z_{i j}^{e_{-} w}$ (ktoe) (thousand tonnes of oil equivalent);

2) Water-related energy usage $z^{e_{-} w}=\sum_{j=1}^{n} \sum_{i=1}^{m} z_{i j}^{e_{-} w}$ (ktoe);

3) Proportion of the water-related energy usage to the total energy usage (\%);

4) Intensity of energy use (may be referred also as energy footprint) in the $j^{\text {th }}$ water resource production $a_{j}^{e_{-} w}=\frac{z_{j}^{e_{-} w}}{x_{j}^{w}}\left(\right.$ toe $\left./ \mathrm{m}^{3}\right)$;

5) Intensity of water-related energy usage (may be referred also as energy footprint of water) $a^{e_{-} w}=\frac{z^{e_{-} w}}{x^{w}}\left(\right.$ toe $\left./ \mathrm{m}^{3}\right)$.

\section{Energy for food indicators:}

1) Energy use in the $j^{\text {th }}$ food resource production $z_{j}^{e_{-} f}=\sum_{i=1}^{m} z_{i j}^{e_{-} f} \quad$ (ktoe);

2) Food-related energy usage $z^{e_{-} f}=\sum_{j=1}^{h} \sum_{i=1}^{m} z_{i j}^{e_{-} f}$ (ktoe);

3) Proportion of the food-related energy usage to the total energy usage (\%);

4) Intensity of energy use in the $f^{\text {th }}$ food resource production $a_{j}^{e_{-} f}=\frac{z_{j}^{e_{-} f}}{x_{j}^{f}}$ (toe/kt);

5) Intensity of food-related energy usage (may be referred also as energy footprint of food) $a^{e_{-} f}=\frac{z^{e_{-} f}}{x^{f}}$ (toe $\left./ \mathrm{kt}\right)$.

\section{Food for energy indicators:}

1) Food resources usage in the $f^{\text {th }}$ energy resource production $Z_{j}^{f_{-} e}=\sum_{i=1}^{m} Z_{i j}^{f_{-} e} \quad$ (kt) (kilo·tonnes);

2) Energy-related food usage $z^{f_{-} e}=\sum_{j=1}^{h} \sum_{i=1}^{m} z_{i j}^{f_{-}} e \quad(\mathrm{kt})$;

3) Proportion of the energy-related food usage to the total food production (\%);

4) Intensity of food usage in the $j^{\text {th }}$ energy resource production $a_{j}^{f_{-} e}=\frac{z_{j}^{f-e}}{x_{j}^{e}}$ (kg/kgoe);

5) Intensity of energy-related food usage (may be referred also as food footprint of energy) $a^{f_{-} e}=\frac{z^{f_{-} e}}{x^{e}}(\mathrm{~kg} / \mathrm{kgoe})$.

\subsection{The W-E-F Nexus Scenarios Analysis}

W-E-F nexus scenarios analysis entails the variations of DRIVERS and INTERVENORS (examples of DRIVERS and INTERVENORS changes are mentioned in section 2.1). Therefore, two levels of scenarios simulation analysis could be performed using the proposed framework to evaluate the W-E-F intersectoral use changes:

1) Scenarios projected based on variation of DRIVERS: the proposed method allows to deal easily with changes in final demands and the resulting changes in intersectoral quantities.

If the superscript " 1 " is used to represent the values of variables after the change in 
demands. Assuming that technology of the water, energy and food production (as represented in $A$ matrix), do not change, the needed total outputs $\left(x^{1}\right)$ caused by new final demand quantities $\left(y^{1}\right)$ are then found as in equation $12\left(x^{1}=L y^{1}\right)$.

These new total quantities are one measure of the impact on the water, energy and food resources of the new final demand quantities.

With this result for $x^{1}$, it is easy to examine the changes in all elements in the intersectoral W-E-F use quantities ( $Z$ matrix) caused by $y^{1}$. From the definition of intensity coefficients, we find $Z^{1}=A \hat{x}^{1}$ along with $y^{1}$, where $\hat{x}$ is the diagonal matrix with the elements of the vector along the main diagonal.

That allows us to deal easily with changes in final demands and the resulting changes in intersectoral quantities. If the superscript " 0 " is used to represent the initial (base year) situation for values of variables. Assuming that W-E-F technology is unchanged $\left(A^{0}=A^{1}=A\right.$ and $\left.L^{0}=L^{1}=L\right)$, let $\Delta x=x^{1}-x^{0}, \Delta y=y^{1}-y^{0}$ and $\Delta Z=Z^{1}-Z^{0}$; so $\Delta Z=A \hat{x}^{1}-A \hat{x}^{0}=A \widehat{\Delta x}$; on the other hand $\Delta x=L y^{1}-L y^{0}=L \Delta y$. Then

$$
\Delta Z=\widehat{A \triangle L y}
$$

2) Scenarios projected based on variation of INTERVENORS: "Best Practice" technology matrix alternatives could be proposed which reflect the W-E-F intersectoral use that are technologically most advanced at present. The W-E-F best practice technology can be defined as those for which the ratios of the intersectoral quantities used to produce one unit of resource are relatively low.

The evaluation of the W-E-F nexus based on variation of intervenors actions is not considered in this study, this issue is under development at our university.

\section{Application and Analysis of Results}

In order to examine the various methodological steps of the proposed approach and to put the developed framework in practice, the developed methodology was applied to evaluate the water, energy and food nexus in Lebanon for the year 2012.

Background information: The population of Lebanon accounts about 4.65 million, the climate is typically Mediterranean, humid to sub-humid in the wet season and semi-arid in the dry season. The wet season coincides with winter period, which lasts from October till May. High population growth and the effect of climate change on water availability are the main challenges facing water demand in the country, with expected higher temperatures, changing rainfall patterns and increased frequency of extreme weather events.

The current agricultural sector largely consists of small-scale, low yielding farms and a limited large-scale commercial farm enterprises. With a growing urbanisation and increasing agricultural exports, Lebanon's demand for food is rising.

Lebanon meets nearly all its energy demand from the import of oil products, because it currently lacks the conventional fossil fuel energy resources and is not effectively benefiting from the available renewable energy resources. The installed thermal power plants are divided into: 1) heavy fuel oil fired steam-turbines (closed cycle); 2) dieselfired combined cycle gas turbines and 3) diesel-fired open cycle gas turbines.

Firstly, this work needs to identify the quantitative elements (inflows) that determine 
the context of the interlinkages of water, energy and food sectors. Ideally, the organisation of these elements should follow standard classifications to facilitate the development of quantitative accounts which are as coherent, consistent and comparable as possible over time and across countries. However, social, institutional, environmental and economic situations that influence W-E-F management policies and strategies vary considerably between countries. Therefore, the structure of some W-E-F nexus accounts could vary according to the specific W-E-F resources conditions in each country.

Within that context, W-E-F nexus inflows that are considered in this study and applied to the Lebanese context are as follows:

Water inflows (including extraction, treatment, conveyance \& distribution) ( $\mathrm{Mm}^{3} /$ year): 1) surface water $\left.(W 1), 2\right)$ groundwater $\left.(W 2), 3\right)$ desalination $\left.(W 3), 4\right)$ wastewater reuse $\left.\left(W_{4}\right), 5\right)$ recycled water and agricultural drainage water reuse $\left(W_{5}\right)$.

Energy inflows (evaluated in terms of primary energy equivalent in ktoe/year on a net calorific value basis): 1) imported petroleum $(E 1), 2)$ electricity (petroleum) $(E 2), 3)$ electricity (hydro) $(E 3), 4)$ imported electricity $(E 4), 5)$ electricity (wind/solar) $(E 5), 6)$ biofuels (E6).

Food inflows (including agriculture, food processing \& transportation) (kt/year): $1)$ irrigated cereals $(F 1), 2)$ irrigated roots and tubers $(F 1), 3)$ irrigated vegetables $(F 2)$, $4)$ irrigated fruits $(F 3), 5)$ other Irrigated agriculture $(F 4), 6)$ livestock-meat $(F 5), 7)$ livestock-milk $(F 6), 8)$ livestock-eggs $(F 7), 9)$ fishing and aquaculture production $(F 8)$, $10)$ rainfed agriculture $(F 9), 11)$ imported agricultural products $(F 10), 12)$ imported livestock products-meat, milk, eggs \& fish ( $F 11)$.

It is important to mention the following remarks:

1) The surface water inflow considered in this study includes water storage, rivers, springs, natural lakes.

2) Hydroelectric-related water usage are only considered if the water withdrawn are for the own use of the hydroelectric power generation.

3) The water resources requirements were analysed vis-à-vis the internally generated water flows to avoid the trans-boundary complexities and uncertainties surrounding external water inflows.

4) The presented case study aimed to put the developed methodology in practice and to verify reliability of the proposed approach, the data used in this case study are compiled by the author for year 2012 from different sources [20]-[29]. The non-available data have been estimated in order to complete testing the proposed method.

Table 1 presents the intersectoral use of W-E-F inflows and the corresponding final demand for year 2012.

By using the developed W-E-F nexus framework presented in section 2, the following results are obtained:

Water for energy indicators: Lebanon's (2012) total primary energy usage was 5523.75 ktoe, and its total energy-related water consumption was $z^{w_{-} e}=2.0 \mathrm{M} \cdot \mathrm{m}^{3}$; the intensity of energy-related water usage (water footprint of energy) $a^{w_{-} e}=0.2 \mathrm{~m}^{3} /$ toe (cubic meter per tonnes of oil equivalent). These results are calculated by excluding hydropower water usage, where the water withdrawal equal to $190 \mathrm{Mm}^{3}$. The total electricity generation was 2721.29 ktoe (primary energy) produced by three fuel oil fired 
Table 1. Intersectoral use of W-E-F inflows and the corresponding final demand for year 2012.

$\begin{array}{llllllllllllllllllllllll}W 1 & W 2 & W 3 & W 4 & W 5 & E 1 & E 2 & E 3 & E 4 & E 5 & E 6 & F 1 & F 2 & F 3 & F 4 & F 5 & F 6 & F 7 & F 8 & F 9 & F 10 & F 11 & F 12 & \begin{array}{l}F i n a l \\ \text { enand }\end{array}\end{array}$

W1 $0.000 \quad 0.000 \quad 0.000 \quad 0.0000 .0000 .0002 .0000 .0000 .0000 .0000 .00067 .32050 .49067 .320114 .1537 .32029 .45329 .4535 .8308 .4150 .0000 .0000 .000 \quad 64.00$

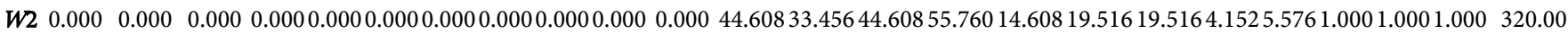

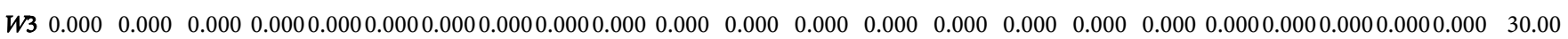

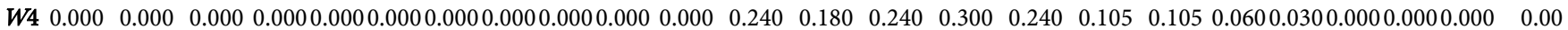

$\begin{array}{llllllllllllllll}\text { W5 } & 0.000 & 0.000 & 0.000 & 0.000 & 0.0000 .0000 .0000 .0000 .0000 .000 & 0.000 & 17.34413 .008 & 17.34421 .680 & 17.344 & 7.588 & 7.588 & 0.8362 .1680 .0000 .0000 .000 & 7.00\end{array}$

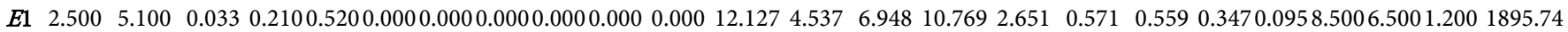

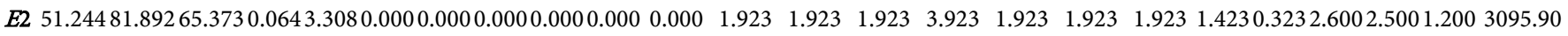

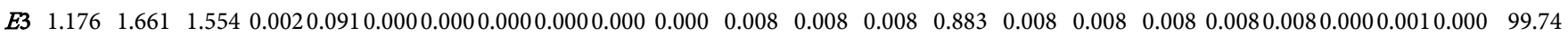

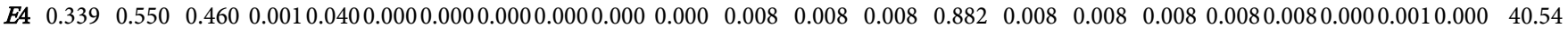

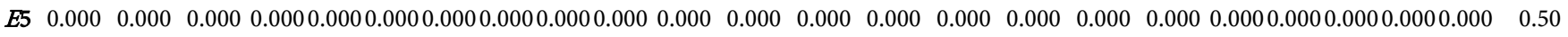

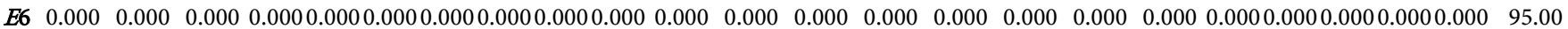

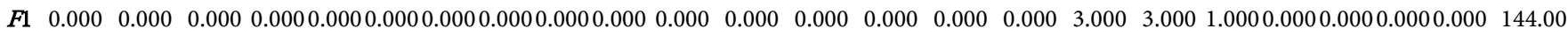

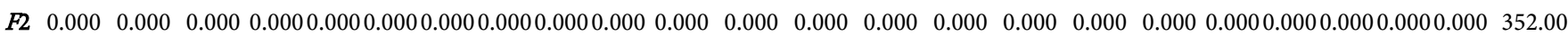

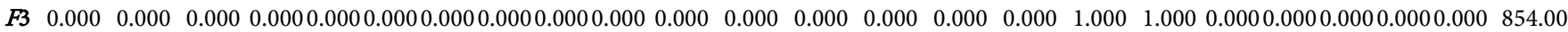

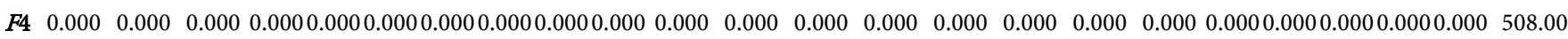

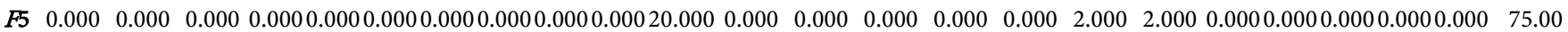

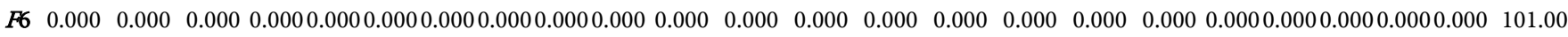

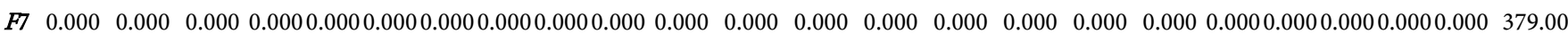

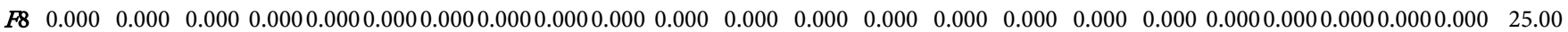

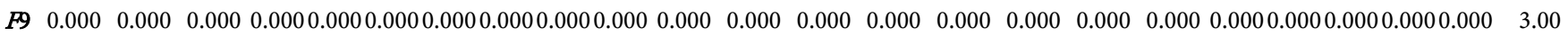

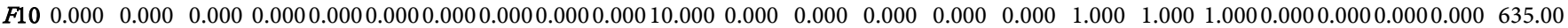

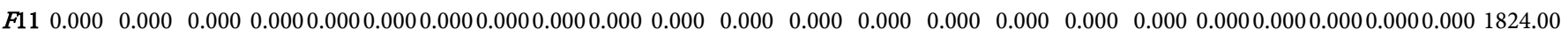

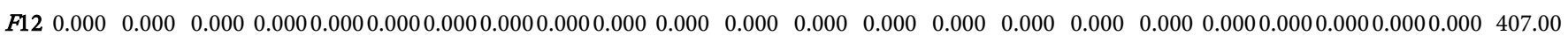

closed cycle steam-turbines plants and four diesel-fired gas turbine plants. Sea water are used for cooling in the most of the installed thermal power plants.

Water for food indicators: Lebanon's (2012) total food-related water consumption was $z^{w_{-} f}=760.95 \mathrm{M} \cdot \mathrm{m}^{3}$ which accounts for $64.27 \%$ of the total water withdrawal; the intensity of food-related water usage (water footprint of food) $a^{w_{-} f}=142 \mathrm{~m}^{3} / \mathrm{t}$. The results shown in Table 2 account for intensities of water use in selected food inflows.

Energy for water indicators: Lebanon's (2012) total water withdrawal was 1183.95 $\mathrm{M} \cdot \mathrm{m}^{3}$, and its total water-related energy consumption was $z^{e^{-}{ }^{w}}=216.12 \mathrm{ktoe}$ which accounts for $3.91 \%$ of the total energy usage; the intensity of water-related energy usage (energy footprint of water) $a^{e_{-} w}=182.5$ toe $/ \mathrm{m}^{3}$.

Energy for food indicators: Lebanon's (2012) total food-related energy consumption was $z^{e_{-} f}=80.21$ ktoe which accounts for $1.61 \%$ of the total energy usage; the intensity of food-related energy usage (energy footprint of food) $a^{e_{-} f}=15$ toe/kt. The results shown in Table 3 account for intensities of energy consumption in selected food inflows. It is important to mention that the energy for food indicators are calculated without taking into account the energy used in fertilizers production. 
Table 2. Intensity of water use in selected water-dependent food production.

\begin{tabular}{cc}
\hline Selected food inflows & $a_{j}^{w-f}\left(\mathrm{~m}^{3} / \mathrm{t}\right)$ \\
\hline Irrigated cereals & 858 \\
Irrigated roots and tubers & 276 \\
Irrigated vegetables & 151 \\
Irrigated fruits & 378 \\
Livestock-meat & 702 \\
Livestock-milk & 561 \\
Imported agricultural products & 1 \\
Imported livestock products & 2.5 \\
\hline
\end{tabular}

Table 3. Intensity of energy use in selected energy-dependent food production.

\begin{tabular}{cc}
\hline Selected food inflows & $a_{j}^{e-f}$ (toe/kt) \\
\hline Irrigated cereals & 93.15 \\
Irrigated roots and tubers & 18.40 \\
Irrigated vegetables & 10.38 \\
Irrigated fruits & 32.40 \\
Livestock-meat & 24.85 \\
Livestock-milk & 17.13 \\
Imported agricultural related food & 4.94 \\
Imported livestock related food & 5.90 \\
\hline
\end{tabular}

Food for energy indicators: There was no biofuel production in 2012 in Lebanon. The use of biomass was limited to final demand for some economic activities or household use.

The W-E-F nexus results mentioned above were for the 2012 situation. A scenario of increase of irrigated food products demand of $20 \%$ will be now considered. The increase in demand could be for example as result of population growth, changes in government spending or changes in consumption patterns. Using the proposed method, it becomes easy to evaluate the total output from the water and energy sectors that would be necessary in order to meet this new demand. In this scenario we assume that the technology of the water, energy and food production (as represented in the $A$ matrix), is unchanged. The resulting changes in intersectoral quantities $(\Delta Z)$ caused by the changes in final demand quantities $(\Delta y)$ are then evaluated. The results could be summarised as follows:

The food-related water consumption will have to increase its output by $z^{w_{-} f}=131.0388 \mathrm{M} \cdot \mathrm{m}^{3}$. Similarly, food-related energy consumption will have to increase its output by $z^{e_{-} f}=10.3203$ ktoe, but, these new intersectoral water and energy (direct) quantities necessitate to produce additional intersectoral (indirect) quantities. Water will ultimately have to increase its direct and indirect outputs by $131.0489 \mathrm{Mm}^{3}$ which accounts for $11.07 \%$ increase in water of the total water withdrawal. Similarly, the energy, in satisfying the new food demand, will have to increase its direct and indirect outputs by 25.8268 ktoe which accounts for $0.47 \%$ increase in energy of the total 
energy usage. Moreover, electricity sector has to increase its production by 17.64 ktoe and the petroleum products by 8.21 ktoe. So, to realize the above mentioned scenario, provision for the necessary additional water, electricity and petroleum products, quantitatively could be calculated.

The proposed approach permit the evaluation of a large number of possible policy scenarios. A complete set of scenarios are under development at our university such as the evaluation of the save that will occur in water and energy due to save in food waste, the evaluation of the save that will occur in energy due to save in water losses, the evaluation of the effect of the replacement of gravity irrigation with pressurized irrigation system (which achieve water savings and require more energy), evaluation of the effects of the upgrade agricultural technologies and investment in high value crops.

\section{Conclusions and Further Developments}

Water, energy and food resources transitions are interconnected and are driven by an increasing population, a changing climate and a growing economy. In order to attain sustainable development goals, it therefore appears that there is a need for integrated quantitative assessments approach considering the cross sector inter-linkages and the competing demand for resources to evaluate future development scenarios at the local, national, regional and global levels.

The method presented in this study is sufficiently relevant to realize a quantitative framework to model the relationship between water, energy and food. It has three advantages that make it particularly well suited to analysing various technological, structural and quantitative changes scenarios:

1) It allows encompassing all the W-E-F nexus intersectoral quantitative usages in inclusive and consistent way that will enable policy makers to manage and plan W-E-F resources in a sustainable manner and to make use or compare with the available national accounts.

2) The nature of proposed framework makes it possible to analyse the water, energy and food as an interconnected system of resources that directly and indirectly affect one another, tracing changes back through sectors interconnections.

3) The construction of the intensity coefficients matrix allows a decomposition of technological, structural and quantitative changes which identifies the sources as well as the direction and magnitude of changes.

The approach could be ultimately extended to analyse the economy's reactions to changes in the water, energy and food nexus system.

Scenarios of changing the technology matrix $A$ by proposing "Best Practice" technology matrix alternatives are not considered in this study; this issue is under development at our university.

\section{References}

[1] Hoff, H. (2011) Understanding the Nexus. Background Paper for the Bonn 2011 Conference: The Water, Energy and Food Security Nexus. Stockholm Environment Institute (SEI), Stockholm.

[2] FAO (2011) Climate Change, Water and Food Security. FAO Water Reports No. 36. Food and Agriculture Organization of the United Nations, Rome. 
[3] FAO (2014) The Water-Energy-Food Nexus-A New Approach in Support of Food Security and Sustainable Agriculture. Food and Agriculture Organization of the United Nations, Rome.

[4] Bizikova, L., Roy, D., Swanson, D., Venema, H.D. and McCandless, M. (2013) The WaterEnergy-Food Security Nexus: Towards a Practical Planning and Decision-Support Framework for Landscape Investment and Risk Management. IISD Report, International Institute for Sustainable Development (IISD), Winnipeg. http://www.iisd.org/pdf/2013/wef nexus 2013.pdf

[5] Waskom, R., Akhbari, M. and Grigg, N. (2014) U.S. Perspective on the Water-Energy-Food Nexus. Completion Report No.116, Colorado Water Institute.

[6] FAO (2013) An Innovative Accounting Framework for the Food-Energy-Water Nexus, Environment and Natural Resources Management. Working Paper No. 56, Food and Agriculture Organisation of the United Nations, Rome.

[7] FAO (2014) The Water-Energy-Food Nexus at FAO, Concept Note. Food and Agriculture Organisation of the United Nations, Rome.

[8] FAO (2014) Walking the Nexus Talk: Assessing the Water-Energy-Food Nexus in the Context of the Sustainable Energy for All Initiative. Food and Agriculture Organisation of the United Nations, Rome.

[9] ICIMOD (2012) Contribution of Himalayan Ecosystems to Water, Energy, and Food Security in South Asia: A Nexus Approach. International Centre for Integrated Mountain Development (ICIMOD), Kathmandu.

[10] UNECE, Task Force on Water-Food-Energy-Ecosystems (2013) Water-Food-Energy-Ecosystems Nexus for Reconciling Different Uses in Transboundary River Basins. UNECE Water Convention Draft Methodology, United Nations Economic Commission for Europe, Geneva.

[11] Boelee, E., Hoa, E. and Chiramba, T. (2014) UNEP's Engagement in the Water-EnergyFood Nexus. Bonn 2014 Conference, Sustainability in the Water-Energy-Food Nexus.

[12] Bizikova, L., Roy, D., Swanson, D., Venema, H.D. and McCandless, M. (2014) WaterEnergy-Food Nexus and Agricultural Investment: A Sustainable Development Guidebook. International Institute for Sustainable Development (IISD), Winnipeg. http://www.iisd.org/pdf/2014/WEF guidebook.pdf

[13] Andrews-Speed, P., Bleischwitz, R., Boersma, T., Johnson, C., Kemp, G. and VanDeveer, S.D. (2012) The Global Resource Nexus: The Struggles for Land, Energy, Food, Water, and Minerals. Transatlantic Academy, Washington DC.

[14] Segerström, R. (2014) Sustainable Service Provision in Cities-Building a City CLEWs Framework. The Nexus 2014: Water, Food, Climate and Energy Conference, North Carolina University, Chapel Hill.

[15] Federal Ministry for Economic Cooperation and Development (BMZ) (2013) Cities and Resource Efficiency-The Urban NEXUS, Federal Government of Germany. http://www2.gtz.de/wbf/4tDx9kw63gma/FactSheet 09 Nexus engl 21052013.pdf

[16] Biggs, E.M., et al. (2015) Sustainable Development and the Water-Energy-Food Nexus: A Perspective on Livelihoods. Environmental Science \& Policy Journal, 54, 389-397. https://doi.org/10.1016/j.envsci.2015.08.002

[17] Endoa, A., Tsuritab, I., Burnettc, K. and Orencio, P.M. (2015) A Review of the Current State of Research on the Water, Energy, and Food Nexus. Journal of Hydrology: Regional Studies, Online.

[18] UNESCWA (2015) Conceptual Frameworks for Understanding the Water, Energy and Food Security Nexus. E/ESCWA/SDPD/2015/WP.2, UNESCWA Working Paper, Beirut.

[19] Miller, R.E. and Blair, P.D. (2009) Input-Output Analysis: Foundations and Extensions. 2nd 
Edition, Cambridge University Press, Cambridge. https://doi.org/10.1017/CBO9780511626982

[20] FAOSTAT (2016) Food and Agriculture Organization of the United Nations (FAO). FAOSTAT Database. http://faostat.fao.org/site/291/default.aspx

[21] FAO-AQUASTAT (2016) Food and Agriculture Organization of the United Nations (FAO). AQUASTAT Database. http://www.fao.org/nr/water/aquastat/data/query/index.html?lang=en

[22] Daccache, A., Ciurana, J.S., Rodriguez Diaz, J.A. and Knox, J.W. (2014) Water and Energy Footprint of Irrigated Agriculture in the Mediterranean Region. Environmental Research Letters, 9, Article ID: 124014. https://doi.org/10.1088/1748-9326/9/12/124014

[23] MEW (2012) National Strategy for the Wastewater Sector. Ministry of Energy and Water, Resolution No. 35, Date 17/10/2012, Beirut.

[24] MEW (2012) National Water Sector Strategy. Ministry of Energy and Water, Resolution No. 2, Date 09/03/2012.

[25] MEW (2010) Policy Paper for the Electricity Sector. Ministry of Energy and Water.

[26] IEA (2016) International Energy Agency (IEA). Statistics Database. https://www.iea.org/statistics

[27] MA (2012) The Overall Results of the Agricultural Census. Ministry of Agriculture. (In Arabic)

[28] CAS (2013) Lebanon National Accounts 2011 Comments and Tables. The Central Administration for Statistics (CAS).

[29] CAS (2016) The Central Administration for Statistics (CAS). CAS Publications. http://www.cas.gov.lb/index.php

\section{Submit or recommend next manuscript to SCIRP and we will provide best service for you:}

Accepting pre-submission inquiries through Email, Facebook, LinkedIn, Twitter, etc. A wide selection of journals (inclusive of 9 subjects, more than 200 journals)

Providing 24-hour high-quality service

User-friendly online submission system

Fair and swift peer-review system

Efficient typesetting and proofreading procedure

Display of the result of downloads and visits, as well as the number of cited articles

Maximum dissemination of your research work

Submit your manuscript at: http://papersubmission.scirp.org/

Or contact cweee@scirp.org 